\title{
From country stereotypes to country emotions to intentions to visit a country: implications for a country as a destination brand
}

\author{
Milena Micevski, Adamantios Diamantopoulos and Fennifer Erdbrügger \\ Department of Business Administration, School of Business, Economics and Statistics, University of Vienna, Vienna, Austria
}

\begin{abstract}
Purpose - This paper aims to draw from the stereotype content model (SCM) to investigate the mediating role of country-triggered emotions on the relationship between country stereotypes and intentions to visit a country as well as the boundary conditions under which such mediation occurs.

Design/methodology/approach - Two-hundred and eighty-three consumers participated in a between-subjects, Web-based study conducted in Hungary. Participants were randomly exposed to one out of six countries that are among the most popular tourist destinations for Hungarian consumers. Moderated-mediation analysis was performed to test the research hypotheses.

Findings - Country stereotypes of competence and warmth positively influence country-related emotions of admiration which, subsequently, transfer to consumer intentions to visit the focal country as a tourism destination. This mediation is moderated by consumers' extraversion, such that intentions to visit are greater for highly extraverted consumers.

Research limitations/implications - Policymakers should take into consideration both the country stereotype and related emotions triggered by this stereotype when developing and promoting the country destination brand. Practitioners should also consider extraversion as a potential personality-based segmentation and targeting variable when communicating a country as a destination brand.

Originality/value - This study delineates the link between country stereotype and affective responses to this stereotype, thus further adding to our understanding of the role that emotions play in determining tourism behavior. It also highlights the role of the personality trait of extraversion as a moderating influence on the stereotype-emotions-visit intentions link.
\end{abstract}

Keywords Country-of-origin, Stereotype content model, Tourism destination, Intentions to visit, Country emotions, Country stereotypes

Paper type Research paper

\section{Introduction}

International marketing literature has long investigated the influence that country image has on perceptions of products coming from different countries, a phenomenon known as the country-of-origin (COO) effect (Diamantopoulos and Zeugner-Roth, 2010). Recent COO research has increasingly been drawing from the stereotype content model (SCM; Fiske et al., 2002) to conceptually underpin the relationship between country-related stereotype and product and brand perceptions, preferences and purchase intentions (Diamantopoulos et al., 2017; Halkias et al., 2016; Magnusson et al., 2019). Evidence suggests that the mere presence of COO cues evokes a set of internally held country stereotypes, namely, socially shared beliefs and judgements about typical features a specific country possesses (Maheswaran, 1994), based on which consumers draw inferences regarding a product's or brand's quality and level of risk when making product/brand choices (Magnusson and et al., 2011; Maheswaran and Chen, 2009; Teas and Agarwal, 2000). Such studies have demonstrated the value of applying a stereotyping perspective to the examination of

The current issue and full text archive of this journal is available on Emerald Insight at: https://www.emerald.com/insight/1061-0421.htm

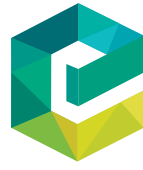

Journal of Product \& Brand Management 30/1 (2021) 118-131

Emerald Publishing Limited [ISSN 1061-0421] [DOI 10.1108/JPBM-09-2019-2563] influences of $\mathrm{COO}$ cues on consumers' reactions to and behavior toward products/brands coming from different countries (Chattalas et al., 2008).

Surprisingly, extant applications of the SCM to COO research (Chattalas and Takada, 2013; Halkias et al., 2016) have mainly investigated the impact of country-related stereotypes on tangible products, leaving the question of such impact on intangible products and, more particularly, on the choice of a country as a tourism destination largely unaddressed. This is despite the fact that the use of country cues is arguably most visible in tourism marketing (Martínez and Alvarez, 2010). Unlike individual products, tourism destinations are more complex in nature and require high levels of consumer involvement at each consumption stage as they

(C) Milena Micevski, Adamantios Diamantopoulos and Jennifer Erdbrügger. Published by Emerald Publishing Limited. This article is published under the Creative Commons Attribution (CC BY 4.0) licence. Anyone may reproduce, distribute, translate and create derivative works of this article (for both commercial and non-commercial purposes), subject to full attribution to the original publication and authors. The full terms of this licence may be seen at http://creativecommons.org/licences/by/4.0/ legalcode

The authors acknowledge the Austrian Science Fund (FWF) for supporting this study (Research Grant: I 3727 - G27).

Received 8 September 2019

Revised 31 January 2020

20 April 2020

8 May 2020

Accepted 9 May 2020 
represent an amalgam of country's products and services (Bigné et al., 2001; Chen and Tsai, 2007; Gnoth, 2002). Being experiential in nature, tourism is thus a heavily imagedriven industry where consumers enter the decision-making process with a unique mind-set - for example, to gain new experiences, to get to know and enjoy different cultures (Morgan et al., 2003). Unlike the decision-making process of tangible products, travellers' decision-making process is a multi-phased (rather than a single-phased) process, in which the consumption is usually separated by space and time; unlike other tangible products, destination product is amorphous in nature including a combination of components - e.g. hospitality, heritage, infrastructure, etc. (Chon, 1990; D'Astous et al., 2008; Litvin and Ling, 2001). This, inevitably, renders the transferability of findings from extant research investigating the effects of $\mathrm{COO}$ cues and evoked country stereotypes on tangible products to the context of tourism product difficult, thus leaving the question of how the content of country stereotypes translates to tourism destination preferences and associated behaviors unanswered.

The popular press provides a plethora of examples of situations where stereotypes do come into play and affect the tourism industry. One such example is the African continent, which still fails to attract a significant amount of world tourists (only 5\% in 2017) (UNWTO, 2018) as a direct consequence of the continent's inability to rebrand and detach itself from very often negatively portrayed images of the continent in the media (e.g. poverty, conflict and disease) (Collins, 2018). Another example is the country of Bangladesh, notorious for its corruption, density in population, pollution and deficiency of tourism-friendly facilities and skilled tourism workers; all these factors placing the country at an unfavourable 120th place among 140 countries assessed for their tourism and travel sector development (The travel and tourism competitiveness report, 2019). Despite the country being famous for its friendliness and hospitality as well as the abundance of unique natural beauty, it is still at the bottom of the list among South Asian countries (Sajid and Islam, 2019). Despite such interest in the popular press, academic literature still lags behind in explaining whether and how stereotypes held by people toward a specific country impact the consumption of country's tourism destination product. Answering these questions, however, is fundamental to managing the country as a brand (Kotler and Gertner, 2002; Papadopoulos and Heslop, 2002; Van Ham, 2001).

In addition, despite the pivotal role emotions play in determining behavioral responses, tourism research has, for the most part, focused on the cognitive aspects of country image and its subsequent impact on consumer behavior (Barroso et al., 2007; Nadeau et al., 2008). The scarce literature that explicitly considers both cognitive and affective components of country image is characterized by a critical shortcoming, namely, that the affective component - which by definition should encompass feelings about the country - has been captured by means of cognitive assessments (such as evaluations of friendliness, trustworthiness and the like; see De Nisco et al., 2015; Elliot et al., 2011; Martínez and Alvarez, 2010). Such assessments should not be mistaken as representing affect evaluations which - correctly interpreted refer to emotions triggered by these cognitive country assessments (Caprariello et al., 2009; Cuddy et al., 2007, 2009). A similar confusion between cognition and affect characterizes the mainstream COO literature where "several items used in the affective dimension of CoI [country image] clearly represent cognitive beliefs rather than emotions and this inclusion under an "affect" scale compromises the content validity of the latter" (Roth and Diamantopoulos, 2009, p. 734).

Finally, it is not known whether there are conditions or situations where the effects of country stereotypes and related emotions on tourism behavior are stronger or weaker. Tourists' decisions regarding a destination product will likely be made in accordance with their self-concept and reflect their preferences (Li and Tsai, 2013; Malamed et al., 1995). As such, the concept of consumer personality has been often cited in the tourism literature as an important determinant of tourist behavior (Gretzel et al., 2004; Melamed et al., 1995). In the context of tourism consumption, an especially influential aspect of personality often cited is consumer extraversion (Barnett, 2006; Li and Tsai, 2013; Lu and Kao, 2009). Yet, the potential boundary effects of extraversion on the relationship between country stereotypes, country-triggered emotions and visit intentions has yet to be investigated.

In an effort to address the above research gaps and to guide practitioners on how to best present and promote a country as a destination brand, we draw from the SCM (Fiske et al., 2002) and the associated behaviors from the intergroup affect and stereotypes map (BIAS; Cuddy et al., 2007) to investigate:

- the emotional responses triggered by stereotypical assessments of a country when viewed as a tourism destination;

- how these emotional responses impact consumers' intentions to visit the focal country; and

- whether consumer extraversion moderates the stereotype $\rightarrow$ emotions $\rightarrow$ intentions to visit relationship.

Our intended contribution is threefold. First, we provide insights into the different emotions that are triggered by consumers' stereotypical assessments of a country as a tourist destination. Second, we identify those emotions that actually impact consumers' intentions to visit the stereotyped country and highlight the role of consumer extraversion in moderating this link. Finally, we offer empirically based guidelines to practitioners on how attention to consumers' stereotypical judgements and the resulting emotions can help in the promotion and management of the country brand for tourism consumption purposes.

In the next section, we present the conceptual framework of our study and derive several research hypotheses. Next, we outline the methods used to collect the empirical data and the measures employed to operationalize the study constructs. We follow this by the presentation of the research results and a discussion of their theoretical and managerial implications. We conclude the paper by reflecting on the study's limitations and offering some suggestions for future research.

\section{Conceptual model and hypotheses development}

Our conceptual framework (shown in Figure 1) represents an adaptation of the SCM framework and the BIAS map from social psychology to a tourism context. Specifically and also consistent with similar applications in a $\mathrm{COO}$ context (Maher and Carter, 2011) - we hypothesize that 


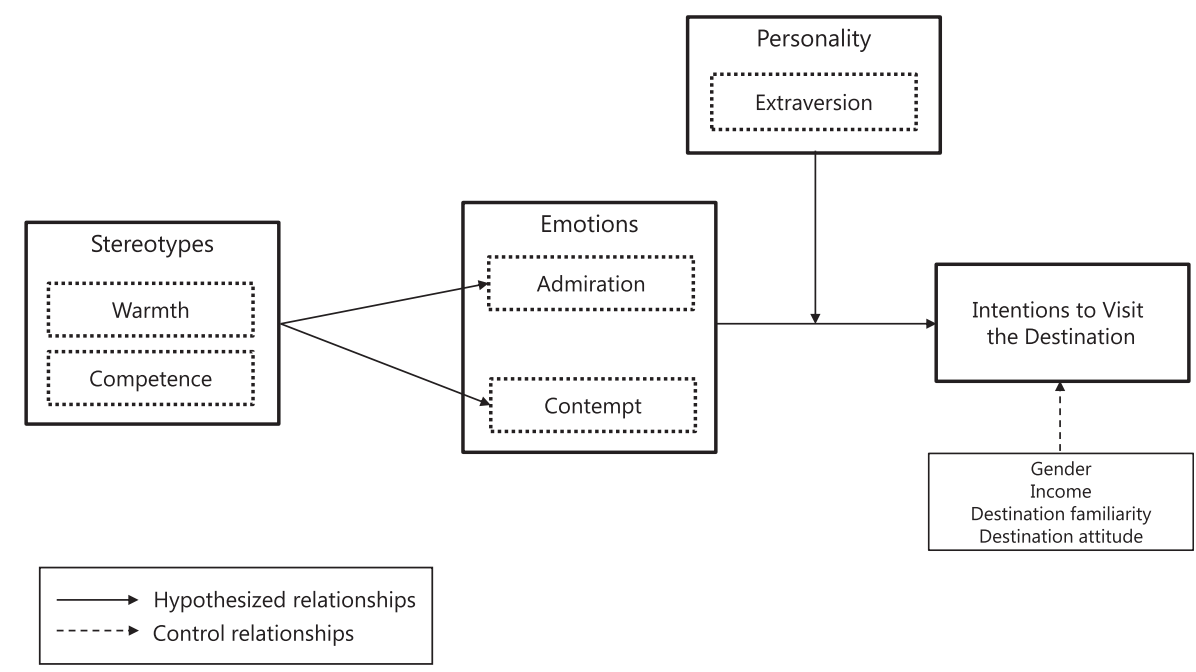

stereotypical assessments of a country in terms of competence and warmth will trigger distinct emotions that, in turn, determine action tendencies (here intentions to visit the stereotyped country). Moreover, we expect that the impact of country-related emotions will be moderated by the degree of consumer extraversion. Thus, formally speaking, we propose a moderated-mediation model (Hayes, 2017) with stereotypical judgements serving as the independent variable, emotions as the mediators and visit intentions as the dependent (outcome) variable. We elaborate on our conceptual framework below.

\subsection{Country stereotypes and country emotions}

Images of a country serve as schemas that influence the patterns of country-related information processing, evoke inferences related to the nature of the country's products and subsequently guide individuals' evaluations of and behavioral responses toward these products (Alexander et al., 2005; Laroche et al., 2005). These schemas contain stereotypical beliefs about the characteristics of a country and such beliefs are generalized across a given population/country (Finkel and Baumeister, 2019). Generally speaking, stereotypes represent "a socially shared set of beliefs about traits that are characteristic of members of a social category" (Greenwald and Banaji, 1995, p. 14) and are the primary basis for forming judgments about social groups and their members. They are subjective and ubiquitous and can be applied to many groups ranging from race, gender, demographic groups and countries among others. Although some are more or less accurate (e.g. men are bigger than women) they could also be a false representation and generalization of a given group (e.g. Greeks are lazy). Nevertheless, stereotypes satisfy the human innate need for cognitive efficiency as they offer a shortcut to meaning by condensing complex information into categories and reducing the amount of information processing time (Levy et al., 1998).

Country stereotypes represent socially shared beliefs and judgements about typical features a specific country possesses (Herz and Diamantopoulos, 2013). Like all stereotypes, country stereotypes by definition involve subjective perceptions because they represent "distinctive characteristics attributed to a country and its inhabitants by some group or groups of outsiders" (Lehtonen, 2005, p. 62). However, the subjective nature of stereotypes does not make them any less influential in decision making processes. Empirical studies relating country stereotypes to evaluations of products and brands originating from these countries show that stereotypical country-level beliefs are automatically evoked (Martin et al., 2011) and subsequently impact the general impressions of and stimulate responses to products, brands and services (Herz and Diamantopoulos, 2013; Liu et al., 2005). To model these effects of country stereotypes on consumers' product assessments and behavioral intentions, COO research has increasingly been drawing on the SCM (Fiske et al., 2002), the later being the most prominent and repeatedly validated theoretical frameworks for understanding the nature of stereotypes (Cuddy et al., 2008; Glick et al., 2006; Halkias and Diamantopoulos, 2020).

According to the SCM, warmth and competence of social groups represent two fundamental cognitive dimensions along which every social group can be described. Based on evolutionary theory (Barkow et al., 1995) and the selfpreservation concept (Jones and Pittnian, 1982), these dimensions tap into the judgments concerning:

- the extent to which a social group (and its members) has positive or negative intentions (i.e. warmth); and

- the ability of that social group to pursue these intentions (i.e. competence) (Cuddy et al., 2008).

Along the warmth dimension, one is able to identify others' intent to help or harm; an individual (or a group) with positive intentions is seen as cooperative, benevolent, kind, friendly and goodnatured. In contrast, an individual (or a group) with negative intentions is perceived as being hostile, cold and unfriendly.

The second stereotype dimension, competence, refers to the capability of others to act in a helpful or a harmful manner (Fiske, 2015). Perceptions of competence may lead to either upward social comparisons (originating from status and respect of highly competent groups), or downward social comparisons (originating from low status and disrespect of incompetent 
groups). An individual (or a group) high in competence is seen as competent, efficient and intelligent. In contrast, an individual (or a group) with low competence is perceived as incompetent, inefficient and incapable.

Warmth and competence may be either negatively or positively related. In the former case, positive judgements on one dimension (e.g. high warmth) are coupled by not so flattering judgements on the other (e.g. low competence). In the latter case, high warmth is accompanied by high competence and low warmth by low competence. For example, in a study examining how European citizens assess European countries along these two dimensions, Germany was stereotyped as a highly competent but cold country, whereas Portugal was seen as a warm but rather incompetent country (Cuddy et al., 2009).

In terms of diagnosticity, previous research indicates that depending on the combination of stereotype dimensions, four clusters of unique emotional responses toward these countries are elicited: admiration (high levels of both warmth and competence), contempt (low levels of competence and low levels of warmth), pity (low levels of competence and high levels of warmth) and envy (high levels of competence and low levels of warmth) (Caprariello et al., 2009; Cuddy et al., 2009). These emotional responses are captured by the BIAS map (Cuddy et al., 2007) according to which stereotypetriggered emotions subsequently translate to positively- or negatively-valenced action tendencies, namely, facilitation and harm (Cuddy et al., 2007). Specifically, univalent combinations of warmth and competence (i.e. high warmth-high competence; low warmth-low competence) result in the univalent emotions of admiration and contempt, respectively. In contrast, mixed stereotypes (i.e. high warmth-low competence or low warmthhigh competence) evoke the ambivalent emotions of pity and envy (Caprariello et al., 2009). Admiration and contempt lead to behavioral tendencies of active facilitation and harm, while pity and envy stimulate passive favorable and unfavorable behavioral tendencies, respectively (Cuddy et al., 2007).

Psychology literature defines admiration as an emotion arising from "extraordinary and praiseworthy actions, performed by a likeable person [...]" (Smith, 2000, p. 185). Research indicates that the admired individuals or groups are indeed seen as desirable (Onu et al., 2016). Moreover, admiration inspires learning from those admired, increases willingness to interact, be close to and cooperate with admired others, and helps overcome in-group evoked biases (Cuddy et al., 2007; Henrich and Gil-White, 2001; Onu et al., 2015). Admiration also heightens attention toward the admired individual or a group and triggers their curiosity about the nature of the admired one's excellence (Henrich and GilWhite, 2001). In a marketing context, admiration has been found to be a principal social emotion influencing consumers to seek and aspire products coming from the admired country thus boosting their purchase intent, brand loyalty and perceived brand prestige (Aaker et al., 2012; Algoe and Haidt, 2009; Kervyn et al., 2012; Maher and Carter, 2011).

H1. Admiration mediates the effect of country's (a) warmth and (b) competence on intentions to visit a country.

While the positive emotion of admiration broadens one's perspective, motivates exploration and is associated with approach motivation and prosocial behaviors (George and
Brief, 1992; Isen and Baron, 1991; Lazarus, 1991), the negative emotion of contempt evokes action tendencies directed toward distancing oneself from the object of contempt and even triggers hostility and exclusion of such individuals or groups (Fischer and Roseman, 2007; Hutcherson and Gross, 2011; Wirtz et al., 2016). Contempt implies a downward social comparison and has a condemning moral aspect to it as it arises from a disapproval of an individual's or group's culpable actions (e.g. breach of widely accepted social standards or human character failures) (Hutcherson and Gross, 2011; Smith, 2000; Steiger and Reyna, 2017). Contemptuous countries are generally disliked as they are seen as inferior, flawed and valueless (Cuddy et al., 2008; Izard, 1977). Existing research on the role of contempt confirms these tendencies and shows that contempt reduces involvement with and felt affinity toward contemptuous companies (Romani et al., 2013). Moreover, compared to other negative social emotions (e.g. anger), contempt has been shown to elicit stronger forms of aggression against the target evoking that emotion (Fischer and Roseman, 2007; Mackie et al., 2000).

H2. Contempt mediates the effect of country's (a) warmth and (b) competence on intentions to visit a country.

Turning attention to passive action tendencies, we expect that envy and pity are less likely to influence consumer responses in a tourism context. Across sociopsychological and marketing research studies, univalent emotions have been found to have stronger effects on both attitudinal and behavioral responses than ambivalent emotions (Ivens et al., 2015). The underlying reason for such differences is grounded in the cognitive consistency paradigm and related theories (Abelson et al., 1968; Gawronski and Strack, 2004), according to which, humans possess an innate need for cognitive consistency and a tendency to perceive the environment in a simple and coherent way. When such cognitive consistency is violated, frustration is prompted. To avoid this noxious state and return to a more harmonious state, individuals either avoid or correct the sources of inconsistency (Festinger, 1957). Emotions of pity and envy as ambivalent types of emotions violate harmonious states of consistency and individuals will seek to reduce the resulting psychological discomfort either by eliminating or reducing the sources of inconsistency (Zajonc, 1960). Therefore, we posit that these emotions will be sidelined and will not take part in the consideration of a country as a potential tourism destination.

\subsection{The moderating impact of consumer extraversion}

Barnett (2006) emphasizes the strong influence of personality mainly extraversion - on individuals' decision-making with regards to travelling and leisure activities. Extraversion is one of the major traits of sensation-seeking tourists who travel without plans, are highly sociable, and strive for authentic experiences (Kahle et al., 2005; Lepp and Gibson, 2008). People scoring high on this personality trait have higher predispositions toward interpersonal and cross-cultural contact and are more likely to invest resources in exploring foreign cultures (Stürmer et al., 2013). Coupled with the role of admiration in eliciting curiosity about the admired country and its ability to increase the willingness to interact with those who are admired, we propose that this emotion's ability to evoke intentions to visit a country 
will be boosted among extraverted people. Furthermore, emotions of admiration toward a foreign country signal possession of prestigious skills which, coupled with the associated need of extraverted people for status and power (Olson and Weber, 2004), should work together to increase the intentions to visit a particular admired country. In turn, the enhanced perceptions of admiration induced by the country stereotypes of warmth and competence should then lead to stronger intentions to visit a country among extraverted people.

H3. The impact of warmth on intentions to visit a country is mediated by the emotion of admiration but this relationship is moderated by extraversion, such that among highly extraverted individuals the positive effect of admiration on intentions to visit a country is strengthened.

H4. The impact of competence on intentions to visit a country is mediated by the emotion of admiration but this relationship is moderated by extraversion, such that among highly extraverted individuals the positive effect of admiration on intentions to visit a country is strengthened.

In the case of contempt, we expect that its negative effect on intentions to visit a country will be attenuated among extraverted individuals. Being adventurous and risk-takers, extraverts exhibit natural curiosity toward unfamiliar outgroups and higher flexibility in intercultural interactions (Ang et al., 2006). Apart from that, extraverts are optimistic and enthusiastic (Barnett, 2006), all of which might work well toward attenuating the negative emotion of contempt. Tourism literature, for example, points to a divergence from the literature investigating $\mathrm{COO}$ effects on product consumption which shows that products from developing countries are more negatively evaluated compared to products coming from developed countries (Samiee, 1994). Contrary to that, tourism research and current travel trends show that developing countries with general negative images due to their low economic, social or technological status, are increasingly becoming popular tourism destinations (Nadeau et al., 2008; Öztürkmen, 2005). This discrepancy might be explained by the types of tourists visiting these countries in that extraverts might be more willing to exhibit tolerance and interest in such countries.

Hence, we hypothesize that:

H5. The impact of warmth on intentions to visit a country is mediated by the emotion of contempt but this relationship is moderated by extraversion, such that among highly extraverted individuals the negative effect of contempt on intentions is attenuated.

H6. The impact of competence on intentions to visit a country is mediated by the emotion of contempt but this relationship is moderated by extraversion, such that among highly extraverted individuals the negative effect of contempt on intentions is attenuated.

\section{Methodology}

\subsection{Data collection}

Two-hundred and eighty-three consumers participated in a between-subjects, Web-based study conducted in Hungary.
Participants were randomly exposed to one out of six countries that are among the most popular (and thus familiar) tourist destinations for Hungarian consumers, namely Spain, Italy, Austria, Finland, Germany and the UK (Világgazdaság, 2016; Österreich Werbung, 2017). The selection of these countries was based on prior research analysing warmth and competence stereotype dimensions of European countries (Cuddy et al., 2009). The chosen countries differ significantly in terms of consumer perceptions of warmth and competence, thus, ensuring sufficient variability in the stereotype dimensions and enhancing the generalizability of research findings. Two-third of the sample is female. The majority, $39.2 \%$ are between 25 and 34 years old. In total, $93.7 \%$ of the participants live in either the capital $(38.96 \%)$ or other cities in Hungary $(54.8 \%)$, while $81 \%$ have a university degree (e.g. bachelor, master or $\mathrm{PhD}$ ). There is also a good variation in terms of income and travel frequency among respondents, with the majority (54.4\%) travelling between 1 and 3 times per year. Table 1 summarizes the characteristics of our sample.

\subsection{Measures}

The stereotypes of the stimuli countries were assessed along the dimensions of competence and warmth, using scale items from Fiske et al. (2002); four attributes captured perceptions of competence (capable, efficient, intelligent, competent) and four attributes captured perceptions of warmth (friendly, goodnatured, kind, warm). The two-item scales for the countryrelated emotions (admiration and contempt) were adopted from Cuddy et al. (2007). The two-item measure for extraversion was borrowed from Gosling et al. (2003), while consumers' intention to visit the focal country was captured by Nadeau et al. (2008) single-item scale. All scales used were operationalized with seven-point response alternatives and showed good reliability (Table 2).

As our sample is skewed toward female respondents, we explicitly control for gender in our model. In addition, to isolate the effects of country stereotypes on the intentions to visit the focal country, we control for familiarity and attitude toward the stimulus country as a tourism destination. Research indicates that the familiarity and positive attitude associated with a destination is an effective predictor of tourist participation, satisfaction and future behavior (Chen et al., 2017; Ragheb and Tate, 1993; Sirgy and Su, 2000). Finally, we include income as a further control variable as income plays an important role in choosing a destination (Morley, 1994).

\subsection{Analysis and results}

The mediating relationships hypothesized in $H 1$ and $H 2$ were tested in two mediation models (PROCESS, Model 4, 5,000 bootstrap resamples) (Hayes, 2017). In the first model, warmth was the independent variable and competence was included as a control variable, whereas in the second model the roles of warmth and competence were reversed.

Regarding the effect of warmth on intentions to visit the focal country via admiration and contempt (H1a and H2a), the direct effect (warmth $\rightarrow$ intentions to visit) was not significant, whereas the total effect was significant $(b=0.57, p<0.001)$, indicating full mediation. More specifically, the indirect effect of warmth on intentions to visit through admiration (warmth $\rightarrow$ admiration $\rightarrow$ intentions to visit) was significant, with 
an estimate of 0.058 and a $95 \%$ bias-corrected (BC) bootstrap confidence interval (CI) between 0.017 and 0.112 . In contrast, the indirect effect of warmth on intentions to visit through contempt (warmth $\rightarrow$ contempt $\rightarrow$ intentions to visit) was nonsignificant ( $\mathrm{b}=-0.002$; BC bootstrap CI: $-0.028-0.024)$. Thus, $H 1 a$ is supported but $H 2 a$ is not.

A similar pattern of results was found for the effect of competence on intentions to visit via admiration and contempt. The direct effect (competence $\rightarrow$ intentions to visit) was not significant, whereas the total effect was significant $(b=0.57$, $p<0.001)$, indicating full mediation. The indirect effect of competence on intentions to visit through admiration (competence $\rightarrow$ admiration $\rightarrow$ intentions to visit) was significant, with an estimate of 0.052 and a $95 \%$ BC bootstrap CI between 0.013 and 0.102 . This supports $H 1 b$. However, as was the case with warmth, the indirect effect of competence on intentions to visit through contempt (competence $\rightarrow$ contempt $\rightarrow$ intentions to visit) was not significant ( $\mathrm{b}=-0.002$; $\mathrm{BC}$ bootstrap CI: $-0.024-0.021$ ), offering no support for $H 2 b$.

In terms of the direct relationships, warmth had a significant positive effect on admiration ( $b=0.24, p<0.05$ ) and a negative effect on contempt $(b=-0.15, p<0.001)$. A similar pattern of results was obtained for the dimension of competence. A significant positive effect on admiration $(b=$ $0.24, p<0.05)$ and negative effect on contempt $(b=-0.11$, $p<0.05$ ) was observed.

To test the moderated-mediating relationships specified in H3-H6, a similar procedure was followed (PROCESS, Model $14,5,000$ bootstrap resamples) with percentile conditioning for the indirect effects (Hayes, 2017). Regarding warmth, the analysis produced a moderated-mediation index (MMI) estimate of 0.032 and BC bootstrap CI of 0.004 to 0.067 , showing that the mediating effect of admiration in the relationship between warmth and intentions to visit differs depending on the level of extraversion of the consumer. Specifically, and consistent with $H 3$, this link is strengthened among extraverted consumers. Regarding competence, the analysis produced a MMI estimate of 0.029 and a BC bootstrap CI of 0.003 to 0.063 , showing that the mediating effect of admiration on the relationship between competence and intention to visit differs depending on the level of extraversion of the consumer. Consistent with H4, this link is also strengthened among extraverted consumers.

Repeating the analysis but using contempt rather than admiration as the mediating variable, resulted in a nonsignificant MMIs for both warmth and competence (MMIwarmth: -0.001 ; BC bootstrap CI: $-0.044-0.013$ and MMI competence: -0.001 ; BC bootstrap CI: $-0.038-0.009)$, thus offering no support for $H 5$ and $H 6$.

To analyze the nature of the expected moderated-mediation relationships in more detail, we probed the conditional indirect effects at different values of the moderator $(-/+1 S D$ from the mean). Consistent with our expectations, at low levels of extraversion, the indirect path warmth $\rightarrow$ admiration $\rightarrow$ intention to visit is non-significant, whereas for medium and high extraversion levels, the path becomes significant. This indicates that the indirect effect of a country's warmth on the intentions to visit a country as a tourism destination via the elicited emotion of admiration toward that country is strengthened among moderately and highly extraverted people. The same
Table 1 Sample profile $(N=283)$

\begin{tabular}{|c|c|c|}
\hline & $n$ & $(\%)$ \\
\hline \multicolumn{3}{|l|}{ Gender } \\
\hline Male & 69 & 24.3 \\
\hline Female & 205 & 72.2 \\
\hline \multicolumn{3}{|l|}{ Age } \\
\hline $18-24$ & 32 & 11.3 \\
\hline $25-34$ & 111 & 39.1 \\
\hline $35-44$ & 32 & 11.3 \\
\hline $45-54$ & 46 & 16.2 \\
\hline $55-64$ & 42 & 14.8 \\
\hline $65+$ & 11 & 3.9 \\
\hline \multicolumn{3}{|l|}{ Income } \\
\hline Less than HUF100K & 29 & 10.2 \\
\hline HUF100K-200 K & 86 & 30.3 \\
\hline HUF $201 \mathrm{~K}-300 \mathrm{~K}$ & 83 & 29.2 \\
\hline HUF $301 \mathrm{~K}$ plus & 76 & 26.8 \\
\hline \multicolumn{3}{|l|}{ Education } \\
\hline Secondary school & 20 & 7.1 \\
\hline High school & 34 & 12.0 \\
\hline Bachelors & 98 & 34.7 \\
\hline Masters & 130 & 45.9 \\
\hline PhD & 1 & 0.4 \\
\hline \multicolumn{3}{|l|}{ Residence } \\
\hline Capital & 110 & 38.9 \\
\hline City & 155 & 54.8 \\
\hline Rural area & 18 & 6.3 \\
\hline \multicolumn{3}{|l|}{ Travel frequency } \\
\hline Less than once a year & 101 & 35.7 \\
\hline Once a year & 88 & 31.1 \\
\hline 2-3 times a year & 66 & 23.3 \\
\hline More than 3 times per year & 28 & 9.9 \\
\hline Note: HUF = Hungarian forin & 35 HUF) & \\
\hline
\end{tabular}

Table 2 Measurement scales

\begin{tabular}{lccc}
\hline & Means & SD & Cronbach's alpha \\
\hline Competence & 3.79 & 0.65 & 0.81 \\
Warmth & 3.73 & 0.85 & 0.93 \\
Admiration & 3.22 & 1.04 & 0.66 \\
Contempt & 1.26 & 0.61 & 0.85 \\
Extraversion & 3.64 & 0.93 & 0.62 \\
Visit intention & 2.89 & 1.12 & $\mathrm{n} / \mathrm{a}$
\end{tabular}

Note: $\mathrm{n} / \mathrm{a}=$ not applicable as single item measure

holds true in the case of competence, with the competence $\rightarrow$ admiration $\rightarrow$ intention to visit becoming stronger as extraversion increases.

\section{Discussion and implications}

4.1 Theoretical implications

"All nations have images, whether deliberately cultivated or not” (Rojas-Méndez et al., 2013, p. 1028). The prominent role 
of country image in selling a country as a destination product lies in the complexity of the tourism product and its experiential nature. Extant tourism literature that focuses on country image and its relations to a destination as a country product often confounds country affect with cognitive aspects of country image (Beerli Palacio et al., 2002; Mossberg and Kleppe, 2005). This confounding has inevitably blurred the role of emotional responses triggered by country stereotypes as determinants of tourism behavior. This is particularly worrisome as the high intangibility aspect of a tourism destination places greater emphasis on consumers' affective perceptions and responses to the evaluation of such a product as compared to that of tangible products (D'Astous et al., 2008).

By applying the SCM and the BIAS map, we contribute to tourism literature by offering a comprehensive understanding of how country stereotypes trigger affective responses that, in turn, determine consumer intentions to visit a particular country. Our focus on country stereotypes adds theoretical value as it enables investigations of country effects in a tourism context at a higher level of abstraction than country image and destination image approaches. Being grounded in a wellestablished theoretical framework (the SCM) which proposes universal, general principles of social stereotyping, our research allows for greater generalizability and comparability. Furthermore, by explicitly including affective responses as mediating variables in our model, we unravel the complexity associated with the relationship between consumers' stereotypical perceptions and their choice of a country as a tourism destination.

In addition, we add to literature by exploring the moderating influence of extraversion in impacting the stereotype $\rightarrow$ emotions $\rightarrow$ intentions to visit link thus furthering our knowledge on the boundary spanning mechanisms that condition this link. Importantly, our findings indicate that only the emotion of admiration mediates the relationship between country stereotypes and intentions to visit a country and that this mediating effect of country admiration is particularly strong among extraverted individuals. Extraverted individuals have a high tendency to seek stimulation and are more willing to travel to and experience foreign countries (Ang et al., 2006; Kahle et al., 2005; Li and Tsai, 2013). As admiration evokes curiosity, it is likely to serve as an additional impulse in extravert's choice of tourist destinations.

Contrary to expectations and while negatively related to both competence and warmth, contempt did not have an effect on visiting intentions, regardless of the respondents' level of extraversion. Perhaps because contempt is more predictable of negative intentions and actions (Fischer and Roseman, 2007), its role in predicting visit intentions as a positive action tendency is limited. Alternatively, the fact that the stimuli destinations used in our study were all highly advanced countries may have resulted in limited levels of contempt which is insufficient to impact behavioral intentions.

Overall, our results support the SCM and the BIAS map as suitable conceptual frameworks for studying the influences of country stereotypes on consumer preferences for a tourism destination product. Contrary to previous tourism research which emphasizes the primacy of affective country images in influencing visit intentions (Elliot et al., 2011) and contrary to $\mathrm{COO}$ research which highlights the role of competence over the role of warmth in eliciting consumer responses (Halkias et al., 2016; Maher and Carter, 2011), our findings demonstrate that both judgments of a country's competence and judgements of its warmth have positive effects on intentions to visit a destination by eliciting admiration. This holds particularly true among extraverted consumers.

\subsection{Managerial implications}

A key managerial implication of our findings is that country stereotypical perceptions affect how consumers assess a country's potential as a tourism destination. This finding is especially relevant to marketers and governments as there is an increasing trend of seeing countries as megabrands in need of effective positioning and promotion for attracting tourists and improving the country's competitive position internationally (Kotler and Gertner, 2002; O'Shaughnessy and O'Shaughnessy, 2000). Marketers and governments are accordingly advised to enhance the perceptions of their country's competence and warmth to reap the benefits of admiration triggered by high levels of these stereotypical dimensions. As a first step in this process, destination marketing organizations (DMOs) should consider establishing a monitoring system that focuses on tracking warmth and competence judgments of their country across potential target markets. Countries can thus, as an immediate step, reinforce the positive stereotypes they might have (e.g. higher warmth and/or higher competence). For example, countries higher in warmth than in competence should focus on portraying their friendliness and welcoming nature in a destination experience context. Similarly, those higher in competence should direct their branding strategies toward their excellence in delivering the experiences or promises advertised and communicated through their promotional efforts.

For those countries that enjoy high levels of both warmth and competence (e.g. France; Cuddy et al., 2009), the goal should be to create a communication strategy built around the emotional attribute of admiration. This can be signalled through communicating those characteristics of a country that are most admirable among the potential target audiences. By focusing on what the target group admires about the country most marketers can increase the benefits of their country's positive stereotypes. One such example is an award-winning tourism campaign of France in 2016, "Fall for France" (http:// us.media.france.fr/en/node/3773), highlighting the worldfamous romantic spirit of the country in a unique and highly artistic manner. This enabled capitalizing not only on the country's emotional appeal but also on France's world-wide accepted role as a country that sets the international standards in art and culture. At the same time, the country carefully promotes its image of skilfulness and competence by showcasing its areas of expertise and unique know-how, for example, portraying the country as excelling in areas of space, aviation and rail industries, pointing to its focus on innovation and successfully promoting the unique, world-famous, savoirfaire of its craft workers (www.bestoffrance.org/).

Importantly, as both warmth and competence elicit the emotion of admiration, DMOs should also strive to improve the stereotypical perceptions of low warmth and/or competence among their potential travellers. To do so, they can engage in several strategies ranging from the: 
- improvement of the existing country stereotypes;

- disassociating of the country as a tourism destination from the general country image toward a more-long term strategic approach of; and

- changing the country stereotypes altogether.

With respect to the first approach, DMOs are advised to engage in activities that generate positive publicity and extensive media coverage thus increasing the international profile of a country and enhancing its global image in general. One such example is successful hosting of world famous events. The Olympics is one such global event that attracts wide media coverage across the globe and gives host countries the opportunity to demonstrate their abilities and create positive country associations and experiences for visitors (Nauright, 2004). For example, Mexico had an opportunity to be portrayed as an advanced nation during the 1968 Olympics (Giffard and Rivenburgh, 2000) and China as both as a high-tech and welcoming, people-oriented country in 2008 (Berkowitz et al., 2007). Similarly, in 2018, the Eurovision competition in Portugal received remarkable media exposure as the most cost-effective Eurovision event in the past decade (http://esctoday.com/166724/eurovision-2018-ebucompliments-rtp-for-hosting-the-best-eurovision-ever/) which showcased the country's capability in organizing such an international event. Such an event was shown to increase the post-event inflow of international tourist not only in Portugal but also in other countries organizing Eurovision competitions (Bard, 2018; Tourism-review, 2018).

To improve their stereotypes, marketers can also engage in a media strategy leading to disconfirmation of negative stereotypes. For example, the use of stereotypes can be discouraged if the target audience is exposed to endorsers who possess counter-stereotypical attributes (Fiske and Neuberg, 1990). Singaporean airlines is one such successful example of stereotype disconfirmation where the company's advertising appeal, the Singaporean girl persona, was created to evoke perceptions of warmth and compensate for the general perceptions of Singapore as a highly competent but not that warm country (www.singaporeair.com/en_UK/us/flyingwithus/our-story/singapore-girl/). Likewise, having competent role models as tourism ambassadors could be a way of mitigating negative stereotypes and projecting an image of country's competence. For example, Guan Moye (aka MoYan), the Chinese Nobel Prize Winner, was appointed as Beijing Tourism Ambassador (Li et al., 2014); Blas Servín, the astronomer, as a tourism ambassador of Paraguay (Hebblethwaite, 2019); and government officials promoted the MekongMoments project running across six countries along the Mekong River (BBC, 2016). A word of caution for marketers is warranted here regarding celebrity endorsement strategy. While observing these atypical endorsers might, also, ultimately result in change of stereotypes (Duval et al., 2000) through a process called individuation (a process in which receivers being exposed to stereotype-disconfirming information start re-thinking the appropriateness of their stereotypes; see Ruscher and Hammer, 1994), the exposure to endorsers should also be accompanied with a carefully tailored counter-stereotypic information (Duval et al., 2000). For these efforts to be successful, visible, relevant and accessible role models are important where the best communicator is one with most credibility in a given context, one with the most information to offer and a message portrayed in a coherent manner (Duval et al., 2000).

Another approach to tackling country's lack of warmth and/ or competence is the disassociation of a country as a tourism destination from its general country image. In this approach, marketers engage in branding, advertising or promotional efforts that deliberately disengage from the negative (or less positive) existing country stereotypes. Through the application of a decomposition strategy marketers and governments can thus focus on specific country components, such as, a country as a destination (rather than an overall country), to still make the country a valid international player in the tourism industry (Tse and Lee, 1993). This is the case with many developing countries nowadays (e.g. Albania, Brasil, Myanmar), which even though they suffer from low economic, technological and social development, are still seen as very interesting and desirable tourism destinations (Martínez and Alvarez, 2010). Therefore, branding of such countries should avoid direct reference to the country's general attributes (e.g. reference to the country's economic capabilities or its political leadership) but instead employ tailored messages focusing on positive characteristics of the destination (e.g. quality of offerings, friendliness of accommodation and other service providers, etc.). For example, targeted advertising of Croatia as a safe European country for tourists (ranked as 24th safest country for tourists to visit; The travel and tourism competitiveness report, 2017) as well as being the filming site of several worldwide popular TV series (e.g. Game of Thrones, James Bond, Star Wars) has overcome the media focus from what once was seen as a conflict ridden, post-war country into one of the top North Mediterranean tourist destinations (Orsini and Ostojic, 2018). Another potential way to enhance destination perceptions is the introduction of smart tourism destinations. Boes et al. (2016), for example, explain how smart destinations increase competitiveness and enhance tourism experience. Such destinations are seen as more efficient and showcase not only the destination's innovative capabilities but also government's and other important stakeholders' engagement and dedication to destination development which all ultimately lead to an increase in destination competitiveness (Buhalis and Amaranggana, 2013).

A more long-term strategy aims at consistent re-branding of the country counter to its stereotypes. According to social role theory, group stereotypes derive from the observations of the typical role behaviors of the group members in their everyday lives either through direct experience with that group or through media exposure (Koenig and Eagly, 2014). Marketers are therefore advised to analyze their country media exposure in the target markets and attempt to promote new images, roles and behaviors as typical of their country that ultimately will also lead to changes in stereotypes. A good example is the launch of the "Incredible India" campaign with an effort of many stakeholders (e.g. Indian Tourism Bureau, Ministry of Tourism, local public figures) to shift the focus away from the commonly portrayed images in the media of the country overwhelmed with poverty and epidemics (Bandyopadhyay and Morais, 2005) toward successfully promoting the country via rich information content as one of the largest world 
economies (7th largest country in the world) that is not only rich in knowledge, history and culture but also a safe country to visit (www.incredibleindia.org/content/incredible-india-v2/en. html). Such actions, however, need to be supplemented by coordinated effort of a variety of stakeholders, such as DMOs, government, business as well as the support and cooperation of the local residents (Avraham and Ketter, 2012). Pedeliento and Kavaratzis (2019), for example, show that any place branding activities need to be designed having in mind both external (i.e. potential visitors) and internal (i.e. local residence) audiences. According to their study, residents play a key role in (re) branding a place as their understanding of the brand and their acceptance of it will ultimately lead to a desired legitimation of the place brand. If place branding is accepted by the local residents, a spill over to their interaction with the visitors will also occur, further enhancing the tourist experience.

Marketers should also take into account the personality trait of extraversion as a segmentation variable and tailor their tourist packages, products and communication to the characteristics of this particular group of travellers (e.g. offering activities with social excitement element and/or portraying destination's adventurous and unknown sites). Those practitioners that successfully manage to reap the benefits of increasing the emotions of admiration toward their country and further tailor their communication efforts and offer those types of destination packages that are likely to appeal to extraverted consumers, will successfully differentiate themselves from the increasing global competition in the tourism industry (Morgan et al., 2011). Marketers could, for example, take into account extraverted people being prone to and enjoying social interaction (Tran et al., 2015) and tailor their advertising messages and offers to portray the socialization aspect of their tourist offerings by showcasing local events and restaurants. In addition, extraverts' curiousness and preference for novel and exploratory travel experiences (Gilchrist et al., 1995) are a good indication for tourism professionals (e.g. agencies) to include such elements in their offerings, such as, for example, diversity of landscapes, abundance of history, less popular or remote areas combined with the social moment of group activities, etc. A good example is the promotion of Inka Trails in Peru (www. incatrail-peru.com/) which combines the following elements in their tour offering: difficult to reach remarkable archaeological sites, a range of landscape formats and small group tour offering. Finally, when creating their advertising campaign, marketers should take into account that:

- extraversion is connected to the use of social media particularly among young adults below 29 years of age (Correa et al., 2010); and

- extraverted people are more inclined toward taking the information from the external environment (e.g. friends and family) when making tourism choices (Horner and Swarbrooke, 2016).

Thus, marketers could place their communication messages on those social media platforms that are likely to be accessed by their potential extraverted customers and their friends and family members.

Especially in an online context, marketers are advised to pay close attention to type of platform used, platform design and how the country symbols are presented in an online environment. Previous research indicates that - especially for experiential platforms (such as destination platforms) where first impressions of the destination are created - platform type, platform design and the content created are all important components of the intention to visit a destination (Molinillo et al., 2018). Distinguishing between the platforms is highly recommendable as tourists' involvement, perceptions and use of available online platforms (e.g. website. Facebook, Instagram etc.) have been shown to differ significantly among tourists. Nevertheless, when carefully tailored to the target group, the content on these platforms present a great opportunity for marketers for eliciting favourable or admirable emotional responses to the destination (Zhang et al., 2018a).

\subsection{Limitations and future research}

Regarding our study's limitations, the destinations used as stimuli were all highly advanced European countries. Given the lack of previous studies applying the SCM and the BIAS map in a tourist destination context, our results should be, therefore, viewed as suggestive and in need of further verification using different tourist destinations as research stimuli. This is particularly important in light of the non-significant results obtained for contempt which may (at least partially) reflect the choice of highly advanced, Western countries as stimuli. Had the later been say, developing countries, contempt might have also (negatively) impacted visit intentions; this offers an interesting direction for future research.

A second limitation is that we solely looked into visit intentions as the dependent variable and did not consider variables that capture consumers' actual behavior. Another avenue for future research could therefore be focusing on consumers' willingness to pay or realized visits to the focal country as well as tourist experiences. Regarding willingness to pay, it is conceivable that - at least for some consumers - highly admired countries may not be actually considered as attractive destinations due to (potentially false) perceptions that the relevant tourist services (e.g. accommodation, attractions, events, etc.) are (too) highly priced. Thus, replacing visit intentions with willingness to pay would furnish additional insights on the predictive ability of admiration as a countryspecific emotion. In addition, country and destination attributes have been shown to impact the creation of memorable tourism experiences, which go beyond the satisfaction with a destination and influence tourist destination loyalty and hence, their revisit intentions (Zhang et al., 2018b). Creation of such memorable experiences is of particular importance in the context of tourism, where even though satisfied, tourist are still highly inclined to gaining new experiences and explore new destinations. Therefore, future research could explore how country stereotypes affect the memorable tourism experiences and their revisit intentions, and whether these affects differ among introverted and extroverted tourists.

Third, leisure tourists have different motives, wants, needs and travel patterns from business tourists (Davidson, 1994; Murphy et al., 2007). Holiday travellers' primary reasons for travelling are leisure and relaxation, their motives are essentially hedonistic and their travelling reflects their personal wants and desires. For the different tourism segment of the business traveller, the relevant motivations are more complex as they are 
often involuntary and visits are frequently limited by work, leaving little opportunity for leisure activities (Kulendran and Wilson, 2000; Kladou et al., 2014). Hence, these two segments exhibit differences in value perceptions and attach different degrees of importance to various facets of tourism offerings (Kashyap and Bojanic, 2000). In this context, previous research illustrates how a favourable country image-tourism type match positively impacts tourism perceptions (Kladou et al., 2014). Differences in motivations for travelling and potential country stereotype-travel type match or a mismatch may also influence the importance of warmth and competence in shaping their intentions toward the country as a business destination. For example, for an export manager, a country's competence might play a bigger role in taking this country into his/her consideration set for a business visit than a country's warmth. Future research is thus needed to explore such differences and document how such match between the country stereotype and the tourism type impacts tourists' intention to visit the focal country.

Also, future research is warranted in the area of the spill-over effect of country stereotypes to specific destination product of a country. Previous research shows that the warmth and competence of a specific destination product (i.e. cities, regions) leads to higher visit intentions (Shen et al., 2019). As suggested by stereotyping literature, it is plausible that a transfer of stereotypical perceptions might occur creating a so called "hallo" response (Madden et al., 2012) whereby the evaluation of stereotypical country perceptions transfers to the evaluation of stereotypical evaluations of specific country destination products. Such insights would enhance our understanding of the interrelations between the country and a specific destination stereotype and explain whether and how judgements of the destination origin operate as a cue for travellers to infer destination's warmth and competence.

Fourth, given that the current study focused exclusively on consumers' extraversion as a moderating variable, future studies should also empirically investigate the role of other personality traits on the link between emotions and behavioral responses in a tourism context. Kahle et al. (2005) assert that while extraverted tourists are highly interested in adventurous, exotic and unknown sites, travellers high on neuroticism tend to avoid trying out things for the first time, they seek familiar places as travel destinations and usually engage into localcommunity based tourism. Hence, this personality trait might have an opposite effect on the admiration-visit intention link to that of extraversion.

Finally, stereotypes are largely formed through media exposure to country-related information and via process of socialization (Askegaard and Ger, 1998; Verlegh and Steenkamp, 1999). Current technological trends have been a breeding ground for the emergence of tech-savvy, more informed and knowledgeable destination consumers who are increasingly relying on online content and social networks for gathering information about destinations (Buhalis and Foerste, 2015). This enhances the potential for higher levels of interactivity between tourism enterprises and consumers who are becoming a central partner in tourism value co-creation (Buhalis and Law, 2008; Buhalis and Foerste, 2015). Taking into consideration these new developments, future research could, for example, apply sentiment analysis (Socher et al.,
2013) to analyze how country stereotypes are presented and communicated via these online platforms and whether they are congruent with the corresponding stereotypes held by the consumers. This would reveal any discrepancies and enable marketers to better tailor their online communication content to potential visitors.

\section{References}

Aaker, J.L., Garbinsky, E.N. and Vohs, K.D. (2012), "Cultivating admiration in brands: warmth, competence, and landing in the golden quadrant", fournal of Consumer Psychology, Vol. 22 No. 2, pp. 191-194.

Abelson, R.P., Aronson, E.E., McGuire, W.J., Newcomb, T. M., Rosenberg, M.J. and Tannenbaum, P.H. (1968), Theories of Cognitive Consistency: A Sourcebook, RandMcNally, Chicago.

Alexander, M.G., Brewer, M.B. and Livingston, R.W. (2005), "Putting stereotype content in context: image theory and interethnic stereotypes", Personality and Social Psychology Bulletin, Vol. 31 No. 6, pp. 781-794.

Algoe, S.B. and Haidt, J. (2009), "Witnessing excellence in action: the 'other-praising' emotions of elevation, gratitude, and admiration", The fournal of Positive Psychology, Vol. 4 No. 2, pp. 105-127.

Ang, S., Van Dyne, L. and Koh, C. (2006), "Personality correlates of the four-factor model of cultural intelligence", Group \& Organization Management, Vol. 31 No. 1, pp. 100-123.

Askegaard, S. and Ger, G. (1998), "Product-country images: towards a contextualized approach", European Advances in Consumer Research, Vol. 31 No. 1, pp. 50-58.

Avraham, E. and Ketter, E. (2012), Media Strategies for Marketing Places in Crisis, Routledge.

Bandyopadhyay, R. and Morais, D. (2005), "Representative dissonance: India's self and western image" Annals of Tourism Research, Vol. 32 No. 4, pp. 1006-1021.

Barkow, J.H., Cosmides, L. and Tooby, J. (1995), The Adapted Mind: Evolutionary Psychology and the Generation of Culture, Oxford University.

Barnett, L.A. (2006), “Accounting for leisure preferences from within: the relative contributions of gender, race or ethnicity, personality, affective style, and motivational orientation", Fournal of Leisure Research, Vol. 38 No. 4, pp. 445-474.

Barroso, C., Armario, E.M. and Ruiz, D.M. (2007), "The influence of market heterogeneity on the relationship between a destination's image and tourists' future behavior", Tourism Management, Vol. 28 No. 1, pp. 175-187.

BBC (2016), "The new tourism trend destination collaboration", available at: www.bbc.com/storyworks/travel/ the-new-tourism-trend/destination-collaboration (accessed 9 January 2020).

Beerli Palacio, A., Díaz Meneses, G. and Pérez Pérez, P.J. (2002), "The configuration of the university image and its relationship with the satisfaction of students", fournal of Educational Administration, Vol. 40 No. 5, pp. 486-505.

Berkowitz, P., Gjermano, G., Gomez, L. and Schafer, G. (2007), "Brand China: using the 2008 olympic games to enhance china's image", Place Branding and Public Diplomacy, Vol. 3 No. 2, pp. 164-178. 
Bigné, J.E., Sanchez, M.I. and Sanchez, J. (2001), “Tourism image, evaluation variables and after purchase behavior: inter-relationship", Tourism Management, Vol. 22 No. 6, pp. 607-616.

Boes, K., Buhalis, D. and Inversini, A. (2016), "Smart tourism destinations: ecosystems for tourism destination competitiveness", International fournal of Tourism Cities, Vol. 2 No. 2, pp. 108-124.

Buhalis, D. and Amaranggana, A. (2013), "Ssmart tourism destinations", in Xiang, Z. and Tussyadiah, I. (Eds), Information and Communication Technologies in Tourism 2014, Springer, Cham, pp. 553-564.

Buhalis, D. and Foerste, M. (2015), "SoCoMo marketing for travel and tourism: empowering co-creation of value", Fournal of Destination Marketing \& Management, Vol. 4 No. 3, pp. 151-161.

Buhalis, D. and Law, R. (2008), "Progress in information technology and tourism management: 20 years on and 10 years after the internet - the state of eTourism research", Tourism Management, Vol. 29 No. 4, pp. 609-623.

Caprariello, P.A., Cuddy, A.J. and Fiske, S.T. (2009), "Social structure shapes cultural stereotypes and emotions: a causal test of the stereotype content model", Group Processes $\mathcal{E}$ Intergroup Relations, Vol. 12 No. 2, pp. 147-155.

Chattalas, M. and Takada, H. (2013), "Warm versus competent countries: national stereotyping effects on expectations of hedonic versus utilitarian product properties", Place Branding and Public Diplomacy, Vol. 9 No. 2, pp. 88-97.

Chattalas, M., Kramer, T. and Takada, H. (2008), "The impact of national stereotypes on the country of origin effect: a conceptual framework", International Marketing Review, Vol. 25 No. 1, pp. 54-74.

Chen, C.C., Chung, J.Y., Gao, J. and Lin, Y.H. (2017), "Destination familiarity and favorability in a country-image context: examining taiwanese travelers' perceptions of China", Fournal of Travel \& Tourism Marketing, Vol. 34 No. 9, pp. 1211-1223.

Chen, C.F. and Tsai, D. (2007), "How destination image and evaluative factors affect behavioral intentions?", Tourism Management, Vol. 28 No. 4, pp. 1115-1122.

Chon, K.S. (1990), "The role of destination image in tourism: a review and discussion", The Tourist Review, Vol. 45 No. 2, pp. 2-9.

Collins, T. (2018), "Rebranding tourism in Africa", available at: https://newafricanmagazine.com/16902/ (accessed 7 January 2020).

Correa, T., Hinsley, A.W. and De ZúÑiga, H.G. (2010), "Who interacts on the web? The intersection of users' personality \& social media use", Computers in Human Behavior, Vol. 26 No. 2, pp. 247-253.

Cuddy, A.J., Fiske, S.T. and Glick, P. (2007), "The BIAS map: behaviors from intergroup affect and stereotypes", fournal of Personality and Social Psychology, Vol. 92 No. 4, pp. 631-648.

Cuddy, A.J., Fiske, S.T. and Glick, P. (2008), "Warmth and competence as universal dimensions of social perception: the stereotype content model and the BIAS map", Advances in Experimental Social Psychology, Vol. 40, pp. 61-149.
Cuddy, A.J., Fiske, S.T., Kwan, V.S., Glick, P., Demoulin, S., Leyens, J.P. and Htun, T.T. (2009), "Stereotype content model across cultures: towards universal similarities and some differences", British fournal of Social Psychology, Vol. 48 No. 1, pp. 1-33.

d'Astous, A., Giraud Voss, Z., Colbert, F., Caru, A., Caldwell, M. and Courvoisier, F. (2008), "Product-country images in the arts: a multi-country study", International Marketing Review, Vol. 25 No. 4, pp. 379-403.

Davidson, R. (1994), Business Travel, Pitman Publishing Limited, London.

De Nisco, A., Mainolfi, G., Marino, V. and Napolitano, M.R. (2015), "Tourism satisfaction effect on general country image, destination image, and post-visit intentions", fournal of Vacation Marketing, Vol. 21 No. 4, pp. 305-317.

Diamantopoulos, A., Florack, A., Halkias, G. and Palcu, J. (2017), "Explicit versus implicit country stereotypes as predictors of product preferences: insights from the stereotype content model", fournal of International Business Studies, Vol. 48 No. 8, pp. 1023-1036.

Diamantopoulos, A. and Zeugner-Roth, K.P. (2010), "Country of origin as Brand element", in Bello D.C. and Griffith D.A. (Eds), Wiley International Encyclopedia of Marketing, JohnWiley \& Sons, Chichester, pp. 18-22.

Duval, L.L., Ruscher, J.B., Welsh, K. and Catanese, S.P. (2000), "Bolstering and undercutting use of the elderly stereotype through communication of exemplars: the role of speaker age and exemplar stereotypicality", Basic and Applied Social Psychology, Vol. 22 No. 3, pp. 137-146.

Elliot, S., Papadopoulos, N. and Kim, S.S. (2011), "An integrative model of place image: exploring relationships between destination, product, and country images", fournal of Travel Research, Vol. 50 No. 5, pp. 520-534.

Festinger, L. (1957), A Theory of Cognitive Dissonance, Row Peterson, Evanston, IL.

Finkel, E.J. and Baumeister, R.F. (2019), Advanced Social Psychology: The State of the Science, Oxford university press, Oxford.

Fischer, A.H. and Roseman, I.J. (2007), "Beat them or ban them: the characteristics and social functions of anger and contempt", Fournal of Personality and Social Psychology, Vol. 93 No. 1, pp. 103-115.

Fiske, S.T. (2015), "Intergroup biases: a focus on stereotype content", Current Opinion in Behavioral Sciences, Vol. 3, pp. 45-50.

Fiske, S.T. and Neuberg, S.L. (1990), "A continuum of impression formation, from category-based to individuating processes: influences of information and motivation on attention and interpretation", in Zanna, M.P. (Ed.), Advances in Experimental Social Psychology, Academic Press, New York, pp. 1-74.

Fiske, S.T., Cuddy, A.J., Glick, P. and Xu, J. (2002), “A model of (often mixed) stereotype content: competence and warmth respectively follow from perceived status and competition", Fournal of Personality and Social Psychology, Vol. 82 No. 6, pp. 878-902.

Gawronski, B. and Strack, F. (2004), “On the propositional nature of cognitive consistency: dissonance changes explicit, but not implicit attitudes", fournal of Experimental Social Psychology, Vol. 40 No. 4, pp. 535-542. 
George, J.M. and Brief, A.P. (1992), "Feeling good-doing good: a conceptual analysis of the mood at workorganizational spontaneity relationship", Psychological Bulletin, Vol. 112 No. 2, pp. 310-329.

Giffard, C.A. and Rivenburgh, N.K. (2000), "News agencies, national images, and global media events", fournalism $\mathcal{E}$ Mass Communication Quarterly, Vol. 77 No. 1, pp. 8-21.

Gilchrist, H., Povey, R., Dickinson, A. and Povey, R. (1995), "The sensation seeking scale: its use in a study of the characteristics of people choosing 'adventure holidays", Personality and Individual Differences, Vol. 19 No. 4, pp. 513-516.

Glick, P., Fiske, S.T., Abrams, D., Dardenne, B., Ferreira, M. C., Gonzalez, R. and Manganelli, A.M. (2006), "AntiAmerican sentiment and america's perceived intent to dominate: an 11-nation study", Basic and Applied Social Psychology, Vol. 28 No. 4, pp. 363-373.

Gnoth, J. (2002), "Leveraging export brands through a tourism destination Brand", fournal of Brand Management, Vol. 9 No. 4, pp. 262-280.

Gosling, S.D., Rentfrow, P.J. and Swann, W.B. Jr, (2003), "A very brief measure of the Big-Five personality domains", Fournal of Research in Personality, Vol. 37 No. 6, pp. 504-528.

Greenwald, A.G. and Banaji, M.R. (1995), "Implicit social cognition: attitudes, self-esteem, and stereotypes", Psychological Review, Vol. 102 No. 1, pp. 4-27.

Gretzel, U., Mitsche, N., Hwang, Y.H. and Fesenmaier, D.R. (2004), "Tell me who you are and I will tell you where to go: use of travel personalities in destination recommendation systems", Information Technology E Tourism, Vol. 7 No. 1, pp. 3-12.

Halkias, G. and Diamantopoulos, A. (2020), "Universal dimensions of individuals' perception: revisiting the operationalization of warmth and competence with a mixedmethod approach", International fournal of Research in Marketing, (in press).

Halkias, G., Davvetas, V. and Diamantopoulos, A. (2016), "The interplay between country stereotypes and perceived brand globalness/localness as drivers of brand preference", Fournal of Business Research, Vol. 69 No. 9, pp. 3621-3628.

Hayes, A.F. (2017), Introduction to Mediation, Moderation, and Conditional Process Analysis: A Regression-Based Approach, Guilford Publications.

Hebblethwaite, M. (2019), Paraguay, The Globe Pequot Press.

Henrich, J. and Gil-White, F.J. (2001), "The evolution of prestige: freely conferred deference as a mechanism for enhancing the benefits of cultural transmission", Evolution and Human Behavior, Vol. 22 No. 3, pp. 165-196.

Herz, M.F. and Diamantopoulos, A. (2013), "Activation of country stereotypes: automaticity, consonance, and impact", Fournal of the Academy of Marketing Science, Vol. 41 No. 4, pp. 400-417.

Horner, S. and Swarbrooke, J. (2016), Consumer Behavior in Tourism, Routlage, New York, NY.

Hutcherson, C.A. and Gross, J.J. (2011), "The moral emotions: a social-functionalist account of anger, disgust, and contempt", Fournal of Personality and Social Psychology, Vol. 100 No. 4, pp. 719-737.

Isen, A.M. and Baron, R.A. (1991), "Positive affect as a factor in organizational behavior", in Staw, B.M. and Cummings,
L.L. (Eds), Research in Organization Behavior, JAI Press, Greenwich, CT, pp. 1-53.

Ivens, B.S., Leischnig, A., Muller, B. and Valta, K. (2015), "On the role of Brand stereotypes in shaping consumer response toward brands: an empirical examination of direct and mediating effects of warmth and competence", Psychology \& Marketing, Vol. 32 No. 8, pp. 808-820.

Izard, C.E. (1977), Human Emotions, Plenum, New York, NY.

Jones, E.E. and Pittnian, T.S. (1982), "Towards a general theory of strategic self-preservation", in Suls, J. (Ed.), Psychological Perspectives on the Self, Erlbaum, Hillsdale, NJ, pp. 231-262.

Kahle, L.R., Matsuura, Y. and Stinson, J. (2005), "Personality and personal values in travel destination preference", $A C R$ Asia-Pacific Advances, Vol. 6, p. 311.

Kashyap, R. and Bojanic, D.C. (2000), "A structural analysis of value, quality, and price perceptions of business and leisure travelers", fournal of Travel Research, Vol. 39 No. 1, pp. 45-51.

Kervyn, N., Fiske, S.T. and Malone, C. (2012), "Brands as intentional agents framework: how perceived intentions and ability can map Brand perception", fournal of Consumer Psychology, Vol. 22 No. 2, pp. 166-176.

Kladou, S., Giannopoulos, A.A. and Assiouras, I. (2014), "Matching tourism type and destination image perceptions in a country context", fournal of Place Management and Development, Vol. 7 No. 2, pp. 141-152.

Koenig, A. and Eagly, A. (2014), "Evidence for the social role theory of stereotype content: observations of groups' roles shape stereotypes", Fournal of Personality and Social Psychology, Vol. 107 No. 3, pp. 371-392.

Kotler, P. and Gertner, D. (2002), "Country as brand, product, and beyond: a place marketing and brand management perspective", Fournal of Brand Management, Vol. 9 No. 4, pp. 249-261.

Kulendran, N. and Wilson, K. (2000), "Modelling business travel”, Tourism Economics, Vol. 6 No. 1, pp. 47-59.

Laroche, M., Papadopoulos, N., Heslop, L.A. and Mourali, M. (2005), "The influence of country image structure on consumer evaluations of foreign products", International Marketing Review, Vol. 22 No. 1, pp. 96-115.

Lazarus, R.S. (1991), "Cognition and motivation in emotion", American Psychologist, Vol. 46 No. 4, pp. 352-367.

Lehtonen, J. (2005), "Stereotypes and collective identification", Cultural Identity in an Intercultural Context, pp. 67-94.

Lepp, A. and Gibson, H. (2008), "Sensation seeking and tourism: tourist role, perception of risk and destination choice", Tourism Management, Vol. 29 No. 4, pp. 740-750.

Levy, S.R., Stroessner, S.J. and Dweck, C.S. (1998), "Stereotype formation and endorsement: the role of implicit theories", Fournal of Personality and Social Psychology, Vol. 74 No. 6, pp. 1421-1436.

Li, C.Y. and Tsai, B.K. (2013), "Impact of extraversion and sensation seeking on international tourism choices", Social Behavior and Personality: An International fournal, Vol. 41 No. 2, pp. 327-333.

Litvin, S.W. and Ling, S.N.S. (2001), "The destination attribute management model: an empirical application to 
bintan, Indonesia", Tourism Management, Vol. 22 No. 5, pp. 481-492.

Liu, S.S., Johnson, K.F. and Johnson, K.F. (2005), "The automatic country-of-origin effects on brand judgments", Fournal of Advertising, Vol. 34 No. 1, pp. 87-97.

Lu, L. and Kao, S.F. (2009), "Direct and indirect effects of personality traits on leisure satisfaction: evidence from a national probability sample in Taiwan", Social Behavior and Personality: An International fournal, Vol. 37 No. 2, pp. 191-192.

Mackie, D.M., Devos, T. and Smith, E.R. (2000), "Intergroup emotions: explaining offensive action tendencies in an intergroup context", fournal of Personality and Social Psychology, Vol. 79 No. 4, pp. 602-616.

Madden, T.J., Roth, M.S. and Dillon, W.R. (2012), "Global product quality and corporate social responsibility perceptions: a cross-national study of halo effects", Fournal of International Marketing, Vol. 20 No. 1, pp. 42-57.

Magnusson, P., Westjohn, S.A. and Zdravkovic, S. (2011), "What? I thought Samsung was Japanese": accurate or not, perceived country of origin matters", International Marketing Review, Vol. 28 No. 5, pp. 454-472.

Magnusson, P., Westjohn, S.A. and Sirianni, N.J. (2019), "Beyond country image favorability: how brand positioning via country personality stereotypes enhances brand evaluations", fournal of International Business Studies, Vol. 50 No. 3, pp. 318-338.

Maher, A.A. and Carter, L.L. (2011), "The affective and cognitive components of country image: perceptions of American products in Kuwait", International Marketing Review, Vol. 28 No. 6, pp. 559-580.

Maheswaran, D. (1994), "Country of origin as a stereotype: effects of consumer expertise and attribute strength on product evaluations", fournal of Consumer Research, Vol. 21 No. 2, pp. 354-365.

Maheswaran, D. and Chen, C.Y. (2009), Nation Equity: Country-of-Origin Effects and Globalization, The SAGE Handbook of International Marketing, Thousand Oaks, CA.

Martin, B.A., Lee, M.S.W. and Lacey, C. (2011), "Countering negative country of origin effects using imagery processing", Fournal of Consumer Behaviour, Vol. 10 No. 2, pp. 80-92.

Martínez, S.C. and Alvarez, M.D. (2010), "Country versus destination image in a developing country", fournal of Travel E̋ Tourism Marketing, Vol. 27 No. 7, pp. 748-764.

Melamed, S., Meir, E. and Samson, A. (1995), "The benefits of personality-leisure congruence: evidence and implications", fournal of Leisure Research, Vol. 27 No. 1, pp. 25-41.

Molinillo, F., Liébana-Cabanillas, F., Anaya-Sánchez, R. and Buhalis, D. (2018), "DMO online platforms: image and intention to visit", Tourism Management, Vol. 65, pp. 116-130.

Morgan, N.J., Pritchard, A. and Piggott, R. (2003), "Destination branding and the role of the stakeholders: the case of New Zealand", Fournal of Vacation Marketing, Vol. 9 No. 3, pp. 285-299.

Morgan, N., Pritchard, A. and Pride, R. (2011), "Tourism places, brands and reputation management", in Morgan, N., Pritchard, A. and Pride, R. (Eds), Destination Brands,
Managing Place Reputation, 3rd ed., ButterworthHeinemann, Oxford, pp. 3-19.

Morley, C.L. (1994), "Experimental destination choice analysis", Annals of Tourism Research, Vol. 21 No. 4, pp. 780-791.

Mossberg, L. and Kleppe, I.A. (2005), "Country and destination image-different or similar image concepts?", The Service Industries fournal, Vol. 25 No. 4, pp. 493-503.

Murphy, L., Benckendorff, P. and Moscardo, G. (2007), "Linking travel motivation, tourist self-image and destination Brand personality", Fournal of Travel \& Tourism Marketing, Vol. 22 No. 2, pp. 45-59.

Nadeau, J., Heslop, L., O'Reilly, N. and Luk, P. (2008), "Destination in a country image context", Annals of Tourism Research, Vol. 35 No. 1, pp. 84-106.

Nauright, J. (2004), “Global games: culture, political economy and sport in the globalized world of the 21 st century", Third World Quarterly, Vol. 25 No. 7, pp. 1325-1336.

O'Shaughnessy, J. and O'Shaughnessy, N.J. (2000), “Treating the nation as a brand: some neglected issues", fournal of Macromarketing, Vol. 20 No. 1, pp. 56-64.

Olson, K.R. and Weber, D.A. (2004), "Relations between big five traits and fundamental motives", Psychological Reports, Vol. 95 No. 7 , pp. 795-802.

Onu, D., Kessler, T., Andonovska-Trajkovska, D., Fritsche, I., Midson, G.R. and Smith, J.R. (2016), "Inspired by the outgroup: a social identity analysis of intergroup admiration", Group Processes Eீ Intergroup Relations, Vol. 19 No. 6, pp. 713-731.

Onu, D., Smith, J.R. and Kessler, T. (2015), "Intergroup emulation: an improvement strategy for lower status groups", Group Processes E Intergroup Relations, Vol. 18 No. 2, pp. 210-224.

Orsini, K. and Ostojic, V. (2018), “Croatia's tourism industry: beyond the sun and sea", European Commission Economic Brief, Vol. 36, pp. 1-13.

Österreich Werbung (2017), "Marktinfo and marktstrategie ungarn. Österreich werbung", available at: www. austriatourism.com/fileadmin/user_upload/Media_Library/ Downloads/OEW_Allgemein/Allgemein/Handbuch_Maerkte/ OeW_Markthandbuch_2017_UNGARN.pdf (accessed 8 July 2019).

Öztürkmen, A. (2005), "Turkish tourism at the door of Europe: perceptions of image in historical and contemporary perspectives", Middle Eastern Studies, Vol. 41 No. 4, pp. 605-621.

Papadopoulos, N. and Heslop, L. (2002), “Country equity and country branding: problems and prospects", fournal of Brand Management, Vol. 9 No. 4, pp. 294-314.

Pedeliento, G. and Kavaratzis, M. (2019), "Bridging the gap between culture, identity and image: a structurationist conceptualization of place brands and place branding", Fournal of Product \& Brand Management, Vol. 28 No. 3, pp. 348-363.

Ragheb, M.G. and Tate, R.L. (1993), “A behavioral model of leisure participation, based on leisure attitude, motivation and satisfaction", Leisure Studies, Vol. 12 No. 1, pp. 61-70.

Rojas-Méndez, J.I., Murphy, S.A. and Papadopoulos, N. (2013), "The US Brand personality: a sino perspective", Fournal of Business Research, Vol. 66 No. 8, pp. 1028-1034. 
Romani, S., Grappi, S. and Bagozzi, R.P. (2013), “My anger is your gain, my contempt your loss: explaining consumer responses to corporate wrongdoing", Psychology $\mathcal{E}$ Marketing, Vol. 30 No. 12, pp. 1029-1042.

Roth, K.P. and Diamantopoulos, A. (2009), "Advancing the country image construct", fournal of Business Research, Vol. 62 No. 7, pp. 726-740.

Ruscher, J.B. and Hammer, E.D. (1994), "Revising disrupted impressions through conversation" Foumal of Personality and Social Psychology, Vol. 66, pp. 530-541.

Sajid, E. and Islam, J. (2019), "Bangladesh tourism sector weakest in South Asia", available at: https://tbsnews.net/ feature/travel/bangladesh-tourism-sector-weakest-south-asia (accessed 18 Jannuary 2020).

Samiee, S. (1994), "Customer evaluation of products in a global market”, fournal of International Business Studies, Vol. 25 No. 3, pp. 579-604.

Shen, X., Lv, X., Lin, S. and Li, C. (2019), "Application of the stereotype content model to destination image: evidence from residents of mainland China", fournal of Destination Marketing E Management, Vol. 14, pp. 1-9.

Sirgy, M.J. and Su, C. (2000), "Destination image, selfcongruity, and travel behavior: toward an integrative model", Fournal of Travel Research, Vol. 38 No. 4, pp. 340-352.

Smith, R.H. (2000), "Assimilative and contrastive emotional reactions to upward and downward social comparisons", in Suls, J. and Wheeler, L. (Eds), Handbook of Social Comparison: Theory and Research, Kluwer Academic/Plenum, pp. 173-200.

Socher, R., Perelygin, A., Wu, J., Chuang, J., Manning, C.D., $\mathrm{Ng}$, A. and Potts, C. (2013), "Recursive deep models for semantic compositionality over a sentiment treebank", in 2013 Proceedings of the conference on empirical methods in natural language processing in Seattle, Washington, DC, pp. 1631-1642.

Steiger, R.L. and Reyna, C. (2017), "Trait contempt, anger, disgust, and moral foundation values", Personality and Individual Differences, Vol. 113, pp. 125-135.

Stürmer, S., Benbow, A.E., Siem, B., Barth, M., Bodansky, A. N. and Lotz-Schmitt, K. (2013), "Psychological foundations of xenophilia: the role of major personality traits in predicting favorable attitudes toward cross-cultural contact and exploration", Fournal of Personality and Social Psychology, Vol. 105 No. 5, pp. 832-851.

Teas, R.K. and Agarwal, S. (2000), "The effects of extrinsic product cues on consumers' perceptions of quality, sacrifice, and value", Fournal of the Academy of Marketing Science, Vol. 28 No. 2, pp. 278-290.

The travel and tourism competitiveness report (2017), available at: www.weforum.org/reports/the-travel-tourismcompetitiveness-report-2017 (accessed 5 January 2020).

The travel and tourism competitiveness report (2019), available at: www.weforum.org/reports/the-travel-tourismcompetitiveness-report-2019 (accessed 15 January 2020).

Tran, X., Nguyen, B.L. and Nguyen, M.C. (2015), "Effects of the big five personality traits on recreation Types - The case of Vietnam tourism", Travel and Tourism Research Association: Advancing Tourism Research Globally, Vol. 14, pp. 1-13.

Tse, D.K. and Lee, W.N. (1993), "Removing negative country images: effects of decomposition, branding, and product experience", fournal of International Marketing, Vol. 1 No. 4, pp. 25-48.

UNWTO (2018), "United nations world tourism organisation, tourism highlights 2018 edition", available at: www.e-unwto. org/doi/pdf/10.18111/9789284419876 (accessed 10 January 2020).

Van Ham, P. (2001), "The rise of the Brand state: the postmodern politics of image and reputation", Foreign Affairs, Vol. 80 No. 5, pp. 2-6.

Verlegh, P.W. and Steenkamp, J.B.E. (1999), "A review and Meta-analysis of country-of-origin research", fournal of Economic Psychology, Vol. 20 No. 5, pp. 521-546.

Világgazdaság (2016), "Ezek voltak a magyarok kedvenc nyaralóhelyei”, Világgazdaság, available at: www.vg.hu/ vallalatok/ezek-voltak-a-magyarok-kedvenc-nyaralohelyei476691/ (accessed 10 July 2019).

Wirtz, C., van der Pligt, J. and Doosje, B. (2016), "Derogating obese individuals: the role of blame, contempt, and disgust", fournal of Applied Social Psychology, Vol. 46 No. 4, pp. 216-228.

Zhang, H., Gordon, S., Buhalis, D. and Ding, X. (2018a), "Experience value cocreation on destination online platforms", Fournal of Travel Research, Vol. 57 No. 8, pp. 1093-1107.

Zhang, H., Wu, Y. and Buhalis, D. (2018b), "A model of perceived image, memorable tourism experiences and re visit intention", Fournal of Destination Marketing \& Management, Vol. 8, pp. 326-336.

\section{Further reading}

Buhalis, D. (2000), "Marketing the competitive destination of the future", Tourism Management, Vol. 21 No. 1, pp. 97-116.

Lotz, S.L. and Hu, M.Y. (2001), "Diluting negative country of origin stereotypes: a social stereotype approach", fournal of Marketing Management, Vol. 17 Nos 1/2, pp. 105-135.

Mowen, J.C. (2000), The 3M Model of Motivation and Personality, Kluwer Academic Press, Boston, MA.

Tourism review (2018), available at: www.tourism-review. $\mathrm{com}$ /portuguese-tourism-benefited-greatly-from-eurovisionnews 10589 (accessed 9 January 2020).

Zajonc, R.B. (2017), "The concepts of balance, congruity, and dissonance", Public Opinion Quarterly, Vol. 24 No. 2, pp. 280-296.

\section{Corresponding author}

Milena Micevski can be contacted at: milena.micevski@ univie.ac.at 